\title{
Vaginal bleeding in a premenarchal girl caused by a high-pressure water fountain in a thermal pool
}

Tjaša Tibaut, Klementina Šafar, Lidija Ouček Farkaš, Zdravko Roškar

\section{Izvleček}

Vaginalna krvavitev pri deklicah pred menarho je redko, a zaskrbljujoče stanje. Pojavi se lahko zaradi različnih vzrokov. O tem, kdaj opraviti pregled $v$ anesteziji in kolposkopijo, strokovnjaki niso enotnega mnenja. Najpogostejši vzrok vaginalne krvavitve je vulvovaginitis, a so pogoste tudi poškodbe med izvajanjem dejavnosti v vodi.

$\checkmark$ prispevku predstavljamo primer šestletne deklice $z$ vaginalno krvavitvijo, ki je nastala zaradi masažnih šob v termalnem bazenu.

Ključne besede: vagina, krvavitev, poškodba, vodne dejavnosti, ginekološki pregled.

\begin{abstract}
Vaginal bleeding in premenarchal girls is a rare but alarming symptom that may have many different causes. Opinions differ as to when a vaginal examination should be performed under general anaesthesia together with colposcopy. The most common cause of vaginal bleeding is vulvovaginitis, followed by traumatic injuries, which can also be caused by water sports.

In this article, we present the case of a six-year-old girl with vaginal bleeding caused by a high-pressure water fountain in a thermal pool.
\end{abstract}

Key words: vagina, bleeding, trauma, aquatic activities, gynaecologic examination. 


\section{Uvod}

Vaginalna krvavitev pri deklicah pred menarho je redka, a zaskrbljujoča. Pojavi se lahko zaradi zelo različnih vzrokov, od malignih tumorjev do spolnih zlorab, lahko pa je idiopatska (1). Potrebna sta natančna anamneza in pregled. Kdaj opraviti pregled $v$ anesteziji in kolposkopijo, strokovnjaki niso enotnega mnenja. Nekateri viri (1) navajajo, da ju moramo opraviti vedno, drugi, da samo $v$ določenih primerih (2). Menimo, da sta nujna vsaj v primerih, ko sumimo, da je vzrok krvavitve poškodba, ko obsega ali mesta poškodbe ne moremo določiti v budnem stanju otroka, ko iščemo tujek ali maligni tumor ter ko ne najdemo nobenega očitnega vzroka krvavitve.

Najpogostejši vzrok vaginalne krvavitve pri deklicah v predpubertetnem obdobju je vulvovaginitis, ki se lahko kaže tudi z vaginalnim izločkom. $V$ večini primerov je vulvovaginitis posledica slabe perinealne higiene (3).

Poškodbo lahko povzroči naključna nesreča, tujek ali spolna zloraba (3). Ker pri otrocih zunanje spolovilo ni posebej zaščiteno, je večkrat izpostavljeno poškodbam. Te so večinoma manjše, a moramo vedno izključiti telesno nasilje ali spolno zlorabo (2). Večinoma so poškodbe posledica padca na oster predmet; najpogosteje so poškodovane velike sramne ustnice, občasno tudi perinej (3). Poškodbe vagine se lahko pojavijo tudi med izvajanjem dejavnosti v vodi, npr. spuščanjem po vodnih toboganih, vodnim smučanjem, vožnjo z vodnim skuterjem ali zadrževanjem nad masažnimi šobami (4), ko voda pod pritiskom vstopi v vagino, jo poškoduje in povzroči obilno krvavitev (5).

Ob nepojasnjeni vaginalni krvavitvi moramo izključiti tumorje na spolovilih (2). Večinoma so benigni (npr. hemangiom, vaginalni polip), a moramo $v$ diferencialni diagnozi pomisliti tudi na botrioidni tumor, embrionalni rabdomiosarkom grozdaste oblike, ki se pri otrocih pojavlja v nožnici, na materničnem vratu, v sečnem mehurju ali nosnem delu žrela (3).

Drugi lokalni vzrok, ki ga opazimo ob pregledu, je prolaps maternice (2), tj. everzija sluznice $v$ uretralnem meatusu navzven. Kaže se kot mehka cirkularna masa, ki izhaja iz vagine in je lahko videti kot vaginalni tumor (3). Izjemno redko se kot vulvarna masa, ki lahko zakrvavi, kaže tudi protruzija ureterokele (6).

Dermatološke spremembe, ki se sicer redko odražajo $z$ vaginalno krvavitvijo, so genitalne bradavice, herpetične spremembe in lichen sclerosus (3).

Če lokalno ne opazimo lezije, moramo pomisliti na hormonske vzroke, ki so lahko endogeni (npr. hormon producirajoči tumorji, prezgodnja puberteta) ali eksogeni (npr. iz materine posteljice v neonatalnem obdobju, zaužitje hormonskih tablet). Pri otrocih so pogosti tudi številni nenavadni vzroki krvavitev, ki jih neredko kljub natančnemu pregledu ne odkrijemo (2).

\section{Predstavitev primera}

Šestletna deklica je bila sprejeta na Otroški oddelek Splošne bolnišnice Murska Sobota zaradi nenadnega pojava sveže krvavitve iz spolovila. $\mathrm{Na}$ dan pojava krvavitve je cel dan preživela $v$ termah, kjer se je $v$ bazenih zadrževala tudi ob masažnih šobah, nad katerimi je sedela. Nenadoma je v bazenu potožila, da mora na stranišče. Z mamo sta opazili prisotnost sveže krvi na papirju in v straniščni školjki. Blata ali urina ob tem ni odvajala. Bolečin ni navajala. Tudi povišane telesne temperature ni imela. Zanikala je dizurične težave ali težave $z$ odvajanjem blata. Tudi možnost poškodbe, tujka in spolne zlorabe so ovrgli.

$\checkmark$ družinski anamnezi je dekličina teta v starosti 21 let umrla zaradi karcinoma jajčnika. $V$ perinatalni in osebni anamnezi posebnosti ni bilo.
Ob kliničnem pregledu deklica ni imela povišane telesne temperature, vrednosti življenjskih parametrov pa so bile $v$ mejah normalnih vrednosti. Iz spolovila je stalno počasi iztekala sveža kri. Zunanje spolovilo in perianalno področje sta bili brez znakov vnetja ali poškodb. Pubertetni stadij po Tannerju smo ocenili s T1, A1, P1.

V laboratorijskih izvidih krvi so bile v hemogramu blago povišane vrednosti levkocitov, preostale vrednosti hemograma pa so bile normalne za starost. $\checkmark$ izvidih preiskav za oceno hemostaze je bila vrednost APTČ na spodnji meji normalnih vrednosti, vrednost TČ pa nekoliko podaljšana za starost. Vrednosti gonadotropinov, prolaktina in spolnih hormonov so bile normalne za starost in predpubertetno obdobje. Kortizol je bil v normalnem razponu, prav tako TSH in ščitnični hormoni. Dodatno smo odvzeli tudi tumorske označevalce alfa fetoprotein (AFP), horiogonadotropin ( $\beta \mathrm{HCG}$ ) in karcinomski antigen 125 (CA 125), katerih vrednosti so bile nizke.

Izvid osnovnega urina je bil normalen, urinokultura negativna.

Ultrazvočna preiskava trebuha je pokazala nehomogeno hiperehogeno gmoto brez doplerskih signalov $v$ nožničnem kanalu (najverjetneje krvni strdki), v osrednjem delu nožnice pa je bila vidna manjša hipoehogena sprememba, ob kateri so bile $z$ doplersko preiskavo jasno vidne pulzacije (sklepali smo, da gre za pulzirajočo arterijo, iz katere je izvirala aktivna krvavitev). Preostali pregledani organi so bili brez posebnosti.

Deklico je v kratkotrajni splošni anesteziji pregledal ginekolog, ki je prepoznal obilo krvnih strdkov v nožničnem kanalu, po njihovi odstranitvi pa izolirano laceracijsko poškodbo nožničnega kanala lateralno $v$ dolžini $2 \mathrm{~cm}$, iz katere je izvirala sveža krvavitev. Drugih poškodb zunanjega ali notranjega spolovila oziroma znakov spolne zlorabe ni ugotavljal. Himen je bil intakten, anularen. Maternični vrat je bil dro- 
ben, ustje brez znakov krvavitve. Rano so kirurško oskrbeli, naredili tri posamezne šive in vstavili nožnični trak, ki so ga po treh urah odstranili. Kontrolni klinični in ultrazvočni pregled po kirurški oskrbi rane je pokazal normalno nožnico in nožnični kanal brez bolezenskih sprememb ali znakov nadaljnje krvavitve. Deklica je bila v kardiocirkulatorno stabilnem stanju odpuščena v domačo oskrbo.

Primer smo kljub odsotnosti kliničnih znakov spolne zlorabe prijavili policiji. Kriminalisti so z deklico, starši in lečečimi zdravniki opravili razgovor. Suma na kaznivo dejanje niso potrdili.

\section{Razpravljanje}

Vzrok vaginalne krvavitve pri deklicah pred menarho moramo vedno natančno raziskati. Veliko informacij pridobimo že z natančno anamnezo in kliničnim pregledom (2). Tudi v našem primeru smo $v$ anamnezi zasledili, da se je deklica tik pred pojavom krvavitve kopala $v$ bazenu ter se igrala in zadrževala nad vodnimi šobami za masažo. V literaturi opisujejo nekaj primerov krvavitev pri mlajših deklicah, ki so posledica vodnih športnih dejavnosti, kot so smučanje na vodi, vožnja s vodnim skuterjem, spuščanje po toboganih ter zadrževanje nad masažnimi šobami $(4,5)$. Takrat namreč vodni curek pod pritiskom silovito vstopi v vagino in lahko povzroči večje raztrganine sluznice, čeprav zunanji znaki poškodbe niso očitni (5). Tudi v našem primeru na zunaj znakov poškodbe ni bilo videti, $2 \mathrm{~cm}$ dolga raztrganina pa se je pokazala ob ginekološkem pregledu v kratkotrajni anesteziji. Ob tem smo rano kirurško oskrbeli in ustavili krvavitev. Odločitev za ginekološki pregled v anesteziji je bila ustrezna, ker je bila krvavitev še vedno aktivna, mesta poškodbe pa v budnem stanju ni bilo mogoče odkriti. Sicer se s poškodbami vaginalne sluznice $z$ vodnim curkom praviloma srečujemo pri odraslih ženskah; pri njih verjetnost poškodbe poveča tudi tujek v vagini (npr. tampon). Nekaj primerov je tudi pri deklicah pred menarho, pri katerih tujek ni predpogoj vaginalne poškodbe $(4,5)$.

V laboratorijskih preiskavah krvi za izključitev drugih možnih vzrokov krvavitve nismo opažali večjih odstopanj. Ob ginekološkem pregledu, pri katerem ginekologinja (razen raztrganine) drugih sprememb ni opažala, smo izključili lokalne vzroke krvavitve. Ker moramo pri vsaki nepojasnjeni poškodbi spolovil pomisliti tudi na spolno zlorabo, smo primer prijavili policiji.

Zavedati se moramo, da tudi ob običajnih dejavnostih v vodi lahko pride do večjih vaginalnih poškodb. Ob sumu nanje je nujna napotitev na ginekološki pregled v narkozi. S pregledom lahko enostavno postavimo diagnozo in hitro ustavimo krvavitev.

Do sedaj zbrana priporočila (5) za preprečevanje podobnih poškodb vključujejo spuščanje po toboganu z nogami skupaj, uporabo neoprenskih oblačil za zaščito in izogibanje uporabi tamponov med izvajanjem dejavnosti $v$ vodi. Ne moremo sicer pričakovati, da bi vsi kopalci za zaščito nosili neoprenska oblačila, a strokovnjaki menijo, da bi lahko ob večji ozaveščenosti običajne kopalke ojačali v perinealnem delu.

\section{Zaključek}

V prispevku smo predstavili primer predpubertetne deklice $z$ vaginalno krvavitvijo, povzročeno z masažnimi šobami v termalnem bazenu. Če se vaginalna krvavitev pojavi pred puberteto, moramo potrditi ali izključiti številne možne vzroke krvavitev, saj se v ozadju lahko skriva resno stanje ali spolna zloraba, ki zahteva ustrezno ukrepanje.
Literatura:

1. Hill NCW, Oppenheimer LW, Morton KE The aetiology of vaginal bleeding in children. A 20-year review. BJOG Int J Obstet Gynaecol 1989; 96(4): 467-70.

2. Söderström HF, Carlsson A, Börjesson A, Elfving M. Vaginal Bleeding in Prepubertal Girls: Etiology and Clinical Management. J Pediatr Adolesc Gynecol 2016; 29(3): 280-5.

3. Fishman A, Paldi E. Vaginal bleeding in premenarchal girls: a review. Obstet Gynecol Surv 1991; 46(7): 457-60

4. Aho T, Upadhyay V. Vaginal water-jet injuries in premenarcheal girls. N Z Med J 2005; 118(1218): U1565.

5. Kunkel NC. Vaginal injury from a water slide in a premenarcheal patient. Pediatr Emerg Care 1998; 14(3): 210-1

6. Méndez-Gallart R, Estevez-Martinez E, Rodriguez-Barca P, García-Palacios M, Bautista-Casasnovas A. Prolapsed cecoureterocele presented as prenatal genital mass: a urological challenge. Can Urol Assoc J 2013; 7(11-12): 757.

Tjaša Tibaut, dr. med.

Zdravstveni dom Murska Sobota, Murska Sobota, Slovenija

Klementina Šafar, dr. med.

Zdravstveni dom Ljutomer, Ljutomer, Slovenija

Lidija Ouček Farkaš, dr. med. Splošna bolnišnica Murska Sobota, Murska Sobota, Slovenija

prim. asist. mag. Zdravko Roškar, dr. med.

(kontaktna oseba / contact person)

Splošna bolnišnica Murska Sobota

Ulica dr. Vrbnjaka 6, 9000 Murska

Sobota, Slovenija

prispelo / received: 30. 3. 2019 sprejeto / accepted: 10. 2. 2020

Tibaut T, Šafar K, Ouček Farkaš L, Roškar Z. $Z$ masažnimi šobami v termalnem bazenu povzročena vaginalna krvavitev pri predpubertetni deklici. Slov Pediatr 2020; 27(1): 31-33. https://doi.org/10.38031/slovpediatr-2020-1-06. 